\title{
DEVELOPMENT OF A NOVEL SECOND-HAND SMOKE REDUCTION DEVICE
}

\author{
M. Moussallem*1,2, J. Jocmek ${ }^{1}$ \\ ${ }^{1}$ Healthy Innovations, Rachiine, Zgharta, Lebanon. \\ ${ }^{2}$ Doctoral School of Sciences and Technology, and Faculty of Public Health, Lebanese \\ University, Tripoli, Lebanon. \\ Corresponding author: Mazen Mousallem \\ mazenphm@hotmail.com
}

(Received January 2018- Accepted March 2019)

\begin{abstract}
M. Moussallem and J. Jocmek. 2019. Development of a novel second-hand smoke reduction device. Lebanese Science Journal. 20(1): 134-147.

Smoking remains a worldwide health hazard. Smokers don't only put themselves at risk of serious health problems, but people around them are also exposed to such potential danger. This passive exposition is called: Second Hand Smoke (SHS). To limit the SHS contamination in an Environmental Tobacco Smoke a new "Healthy Second Hand Smoke (HSHS)" device was developed. In this paper, we will explain the functioning basics of the HSHS device. It is mainly based on an insulated smoke compartment with transparent view, placed in the area where smokers and non-smokers exist together. Smoker inhales and exhales smoke through an "HSHS" accessory called "hand" which is related to the compartment by two hoses. In this compartment, an aspiration system is used to evacuate the smoke. The efficiency of the "HSHS" device is then evaluated. For four hookah smokers, the Carbone monoxide gas concentration was measured during 30 min in a $5.3 \mathrm{~m}^{3}$ unventilated experimental room. A comparison was made between the smoke concentration in the unventilated room, with and without the use of the HSHS device. Statistical tests were performed in order to insure the validity of the results that were taken for four smokers only. The results show that the use of HSHS device reduces second hand hookah inhalation smoke, in a $5.3 \mathrm{~m}^{3}$ unventilated room, by $95.9 \% \pm 28.2 \%, 91.8 \% \pm 37.5 \%, 97.8 \% \pm 15.7 \%$ and $98.5 \% \pm 66.2 \%$ during 10, 15, 20 and 25 minutes respectively. As a conclusion, this new smoking concept opens the way for less invasive smoking habits in crowded environments.
\end{abstract}

http://dx.doi.org/10.22453/LSJ-020.1.134-147 National Council for Scientific Research - Lebanon 2018® lsj.cnrs.edu.lb/vol-20-no-1-2019/ 
Keywords: Healthy Second Hand Smoke; smoking; passive smoking; Environmental Tobacco Smoke.

\section{INTRODUCTION}

Smoking consumption prevalence remains a threat to the health of the world population ( $\mathrm{Ng}$ et al., 2012). A recent systematic analysis in the "Global Burden of Disease Study" showed that tobacco is the second most important disease risk factor (GBD 2013 Risk Factors Collaborators). Therefore, more efforts were made in order to find effective treatments for the diseases caused by smoking (Moussallem et al., 2012; Linmiao et al., 2016; PDQ Adult Treatment Editorial Board, 2016). However, quitting or reducing smoking remains the most effective way to reduce the risk of premature death and disability. It has been shown that people with lung cancer may benefit from smoking abstinence (Linmiao et al., 2016). For regular smokers, a large number of propositions were established in order to reduce the risks caused by smoking. For example, the electronic cigarette (e-cigarette) have been recently introduced, but its real advantage is still under debate in the scientific community (Tayyarah et al., 2014; Farsalinos et al., 2015; Rowell et al., 2015; Hajek et al., 2014; Jieming Zhong et al., 2016; Regan et al., 2013; Gerald et al., 2014). In addition, the cigarette tax has been increased as well (Anne et al., 2016).

Despite the efforts made, the health risks caused by smoking still exist, especially as a result to the continuous use of hookah, that is also referred to as Shisha, Narghile, Waterpipe, Hubble Hubble, Goza (Kamal et al., 2009; Linda et al., 2015; WHO Study Group on Tobacco Product Regulation, 2005; Kiter et al., 2000). The smoke inhaled through hookah, contains toxicants similar to conventional cigarettes such as hydrocarbons, carbon monoxide, and carcinogenic polycyclic aromatic volatile aldehydes (Tayyarah et al., 2014; Kamal et al., 2009; WHO Study Group on Tobacco Product Regulation, 2005; Kiter et al., 2000). A single hookah smoking session typically lasts for 45 minutes and may produce 50 to 100 times the smoke volume inhaled from a single cigarette (Lipkus et al., 2011; Rastam et al., 2011; Primacket al., 2012; Alzoubi et al., 2013; Maziak et al., 2013). Therefore, recent study in the US (Linda et al., 2015), focused on marketing aspects and related regulation of hookah smoking, especially among women, adolescents, and young adults.

Smoking affects, not only the smoker, but also people around him. The inhalation of smoke by persons other than the intended "active" smoker, is called Second Hand Smoke (SHS), or passive smoking in an Environmental Tobacco Smoke (ETS). Therefore, smokers don't only put themselves at serious risk of health problems, but people around them are also exposed to these risks (WHO Report on tobacco smoke and child health: consultation report, 1999; Li et al., 2003; International Agency for Research on Cancer IARC. Monographs Programmme on theEvaluation of Carcinogenic Risks to Human, 2002; Vassiliki et al., 2009; Hamer et al., 2010; Shiue et al., 2014; Chen et al., 2015; Gao et al., 2015). In particular, children's exposure to SHS 
is considered a serious threat on their health as they inhale a mixture of carcinogens, volatile toxins and chemicals (WHO Report on tobacco smoke and child health: consultation report, 1999; International Agency for Research on Cancer IARC. Monographs Programmme on theEvaluation of Carcinogenic Risks to Human, 2002; Vassiliki et al., 2009; Chen et al., 2015).

In order to limit SHS, several devices of air cleaners (such as Smokeless Grabber and GESPERT Ashtray...) were designed to absorb smoke from cigarettes and cigars by using charcoal filtration (Arlene et al., 2011; Coggins et al., 2008; Wampler et al., 1995). These air filtration devices were largely commercialized but limited number of scientific papers show their efficiency. In fact, the previous mentioned papers (Arlene et al., 2011; Coggins et al., 2008; Wampler et al., 1995) demonstrate that, the use of these air cleaners does not reduce significantly the percentage of nicotine in the air. The air cleaners reduce particulate matter (PM) more than they reduce the gas-vapor nicotine. In addition, when the person removes his cigar or cigarette from the air cleaner device in order to smoke, the efficiency of filtration decreases largely since the smoking tool becomes far from the device. Since the air cleaner devices are not totally efficient and a lot of people don't obey to the strict regulations that were established to avoid SHS contamination (Li et al., 2003; Hamer et al., 2010; Shiue et al., 2014; Nakkash et al., 2018), it was necessary to find other solutions for this problem.

In this paper we propose an effective device labeled "Healthy Second Hand Smoked (HSHS)" that is used to reduce SHS caused by any kind of smoking tools: Hookah, Cigarette, Cigar, and Pipe... The HSHS is protected by a Lebanese patent (number: LB 10915). The operation basics of this device will be explained and the first implementations will be shown in the next section of the paper. Moreover, the efficiency of the device will be evaluated by measuring the hookah smoke concentration nearby a smoker, with and without the use of the HSHS device.

\section{MATERIALS AND METHODS}

The new smoking device was constructed in a way to fulfill few criteria. First of all, the device is intended to be used at crowded places. Second, the device allows the smoker to see the exhaled smoke within the device, thus preserving a part of the visual normal smoking pleasure. Finally, the use of this device should be easy and not highly different from the normal smoking manner.

To reach those goals, the "Healthy Innovations" Company have conceived the HSHS device (Figure 1). The approach was based on confining the smoke into an isolated compartment in such a way that the ETS area becomes isolated from the smokers and non-smokers and the smoke does not pollute the room environment. Furthermore, the superior part of the HSHS was made by a transparent material that enables the smokers to see through it, and thus preserve the visual pleasure. The hookah 
and/or cigarette (or any other kind of smoking tools: Cigar, Pipe, etc.), should be placed inside the HSHS device.

A first hose was connected to the hookah and/or cigarette that is placed inside the HSHS. It allows the smoker to inhale the smoke produced by the smoking tool. On the other hand, the smoker exhaled the smoke through a second hose connected to HSHS. For easier use of hoses, and to minimize the smoke leakage from the smoker's mouth while exchanging the inhalation and exhalation hoses, the two hoses were related to a single pipe. The smoker uses the same terminal pipe for inhalation and exhalation of smoke. To prevent that the exhaled smoke enters in the inhalation hose, and vice versa, an HSHS accessory called "hand" is used. It consists of two opposite one-way air check valves that are connected parallel to each other (Figure 2). Each valve is connected to its specific hose in such a way that the smoke moves in the desired direction. This "Hand" was produced by the "Healthy Innovations" Company but it was not protected by a patent. This decision was made by the company in order that the "hand" be accessible to every smoker at a good price. This notion will be detailed in the "results and discussion" section of this study. In addition, a vacuum pomp is used in order to remove the smoke from the HSHS device and threw it outside the ETS region, through an air hose. Furthermore, in order to facilitate air circulation and to avoid increasing pumping pressure inside the HSHS chamber, a second hose was connected from the HSHS device to a pure air environmental region.
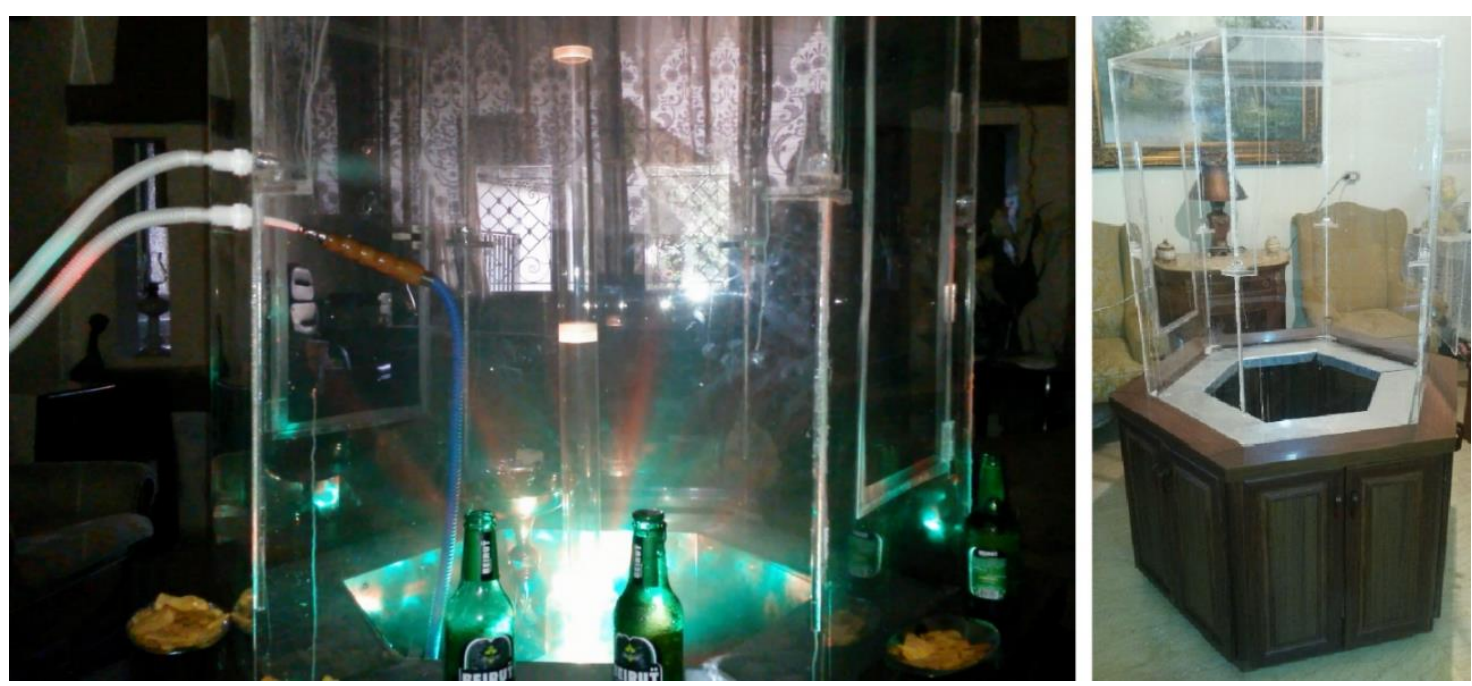

Figure 1. A large size HSHS device: during smoking on the left side and a general external view on the right side.

In order to evaluate the HSHS device efficiency, a series of measurements were conducted. Only Carbon monoxide (CO) gas concentration (ppm: parts per million) produced by hookah smoke was collected. Many other more harmful chemicals presented in the hookah smoke were not collected in our study because our aim was just to know the concentration of hookah smoke in the air. This smoke concentration is 
related to the SHS contamination level and it is proportional to Carbone monoxide concentration. A comparison of the Carbone monoxide gas concentration was made with and without the use of a small size of HSHS device (designed for the use of just one person). All hookah sessions were conducted in a $5.3 \mathrm{~m}^{3}$ (width $=1.1 \mathrm{~m}$, length $=$ $2.2 \mathrm{~m}$ and height $=2.2 \mathrm{~m}$ ) unventilated experimental room (Figure 3 ). The use of a small HSHS device (size $0.25 \mathrm{~m}^{3}$ ) was necessary in order to keep the volume of air in the unventilated room practically unchanged. Subjects were chosen according to some criteria such as their age $(21 \leq$ age $\leq 54)$, number of sessions per day (hookah sessions $\geq$ 1 session/day), product preference (standard conventional Lebanese hookah) and a stable preference for the specified products ( $\geq 6$ months). All subjects were required to abstain from any tobacco product use for a minimum of one hour prior to the collection sessions. Exhaled carbon monoxide levels were verified for the subjects prior to each session and were required to be $0 \mathrm{ppm}$ to participate in the sessions. A total of four subjects were recruited for this study. Subjects used a single session of 30 minutes in a regular puffing regime. All these sessions were repeated two times, with and without the use of the HSHS device (a total of 8 sessions: 2 sessions for each subject).
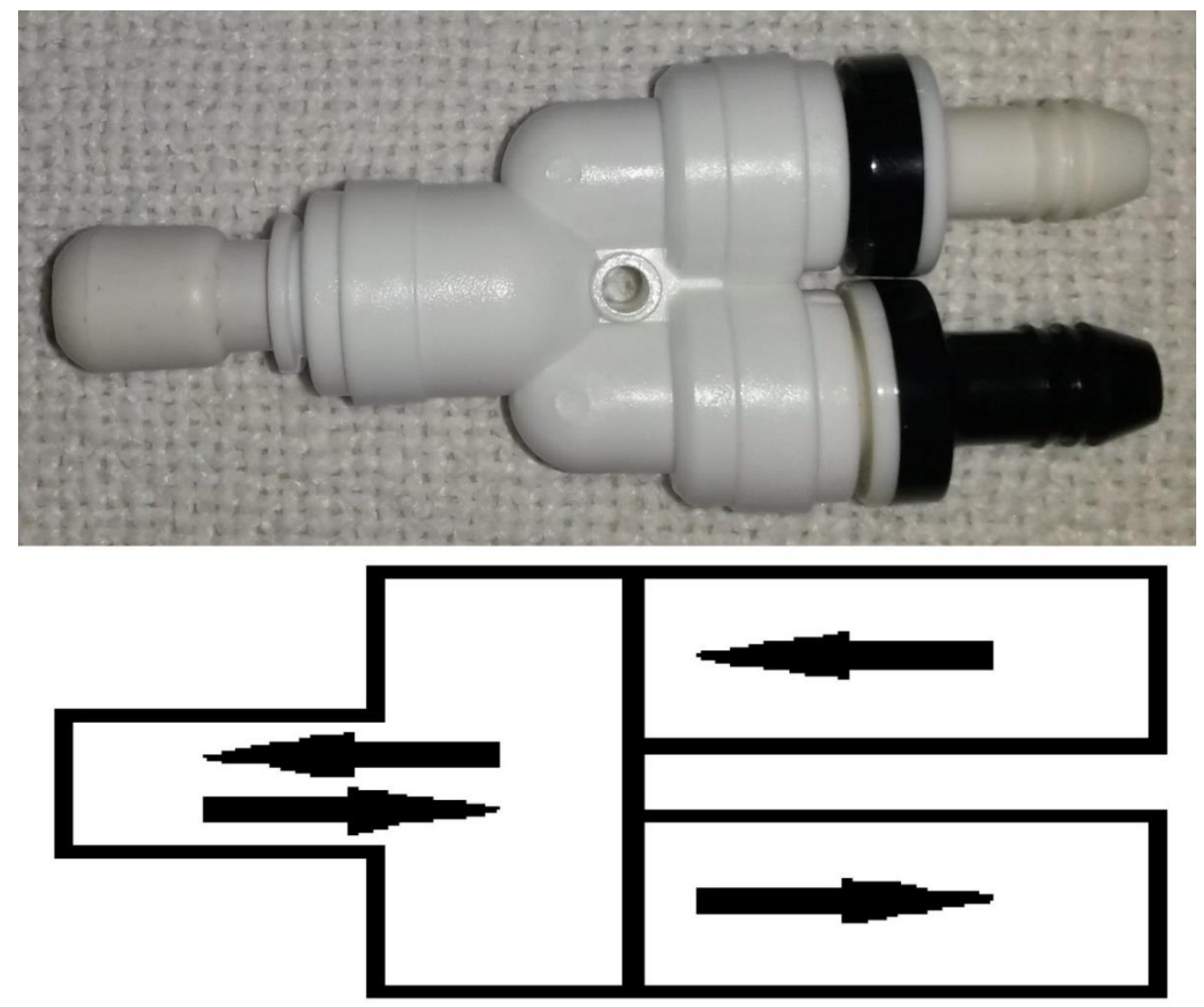

Figure 2. The upper side of the figure shows the hand used in this study. The lower side of it shows the corresponding schema of the interior design. The arrows indicate the permitted direction for air passage. 
For each session, $\mathrm{CO}$ concentration was collected every 5 minutes (from 0 to 30 minutes) during normal exhaled smoke breath. Measurements were done approximately in the center of the unventilated experimental room by placing a Battery-Operated $\mathrm{CO}$ Carbon Monoxide Smoke Detector (OEM brand name). This electrochemical CO sensor type is a digital LCD used to display detection of carbon monoxide gas concentration (ppm). It is especially specified by an adequate temperature, humidity and detecting level respectively between $0 \sim 50{ }^{\circ} \mathrm{C}, 10 \% \sim 95 \%$ and $000 \sim 999 \mathrm{ppm}$. In addition, the background levels of carbon monoxide gas concentration in the unventilated experimental room air were collected prior to smoke exhaled hookah sessions. A security system was followed in order to monitor volunteers inside the unventilated experimental room. Medical intervention was taken in place in case of suspected chemical asphyxiation. For this reason, in order to minimize probability of people's chemical asphyxiation, we have included only 4 subjects in our study. Furthermore, in order to examine the power of this small sample size (only 4 subjects), inferential statistics tests were performed by using SPSS software version 16.0.

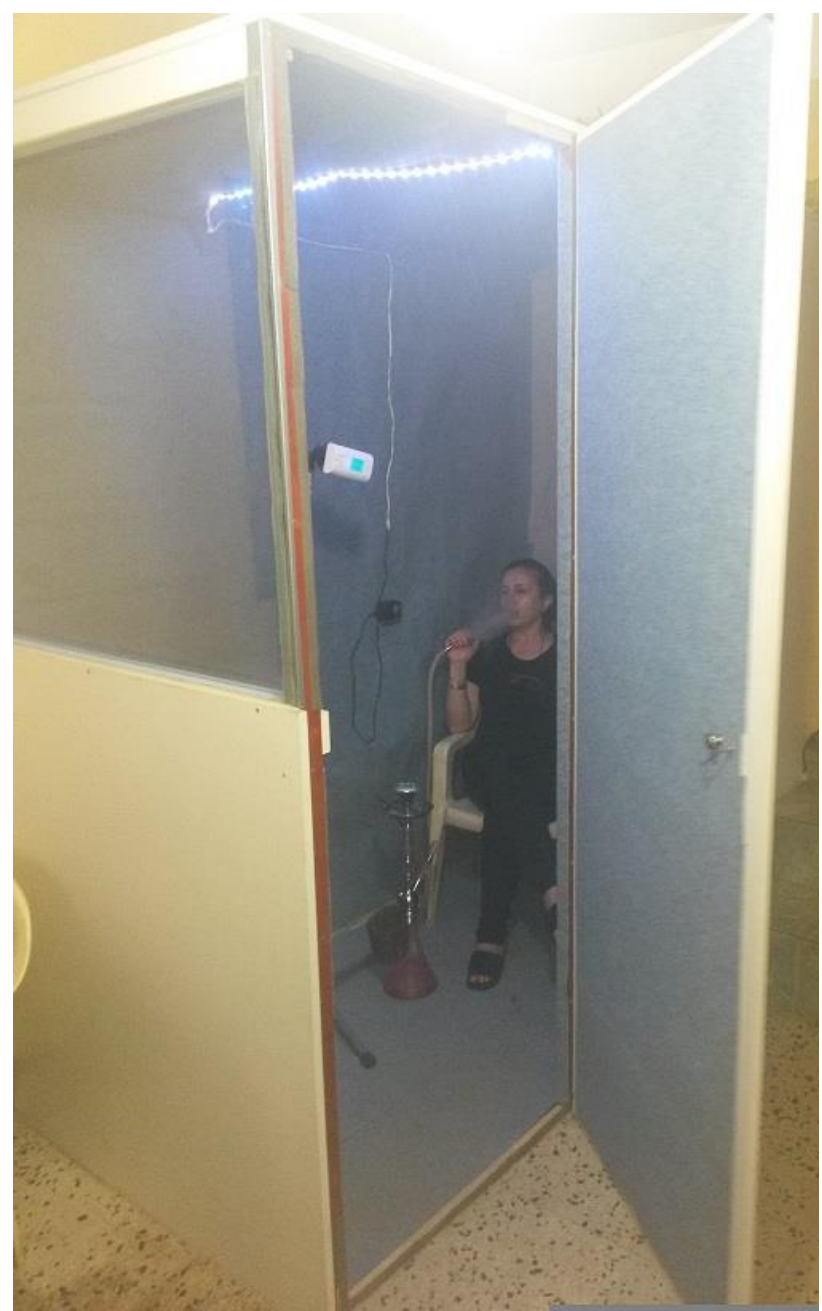

Figure 3. A smoker in the unventilated experimental room used in this study. 


\section{RESULTS AND DISCUSSION}

Table 1 shows the carbon monoxide gas concentration ( $\mathrm{ppm})$ in the unventilated room. For the four subjects, carbon monoxide gas concentration was growing significantly in time when HSHS device was not used. In contrast, HSHS device limited the measured CO levels. Figure 4 shows the relation between the four subjects' average carbon monoxide gas concentration (with the corresponded standard deviation) and time, with and without the use of the HSHS device ("Mean Without for the 4 subjects", "SD Without for the 4 subjects", "Mean With for the 4 subjects", and "SD With for the 4 subjects" in Table 1 ).

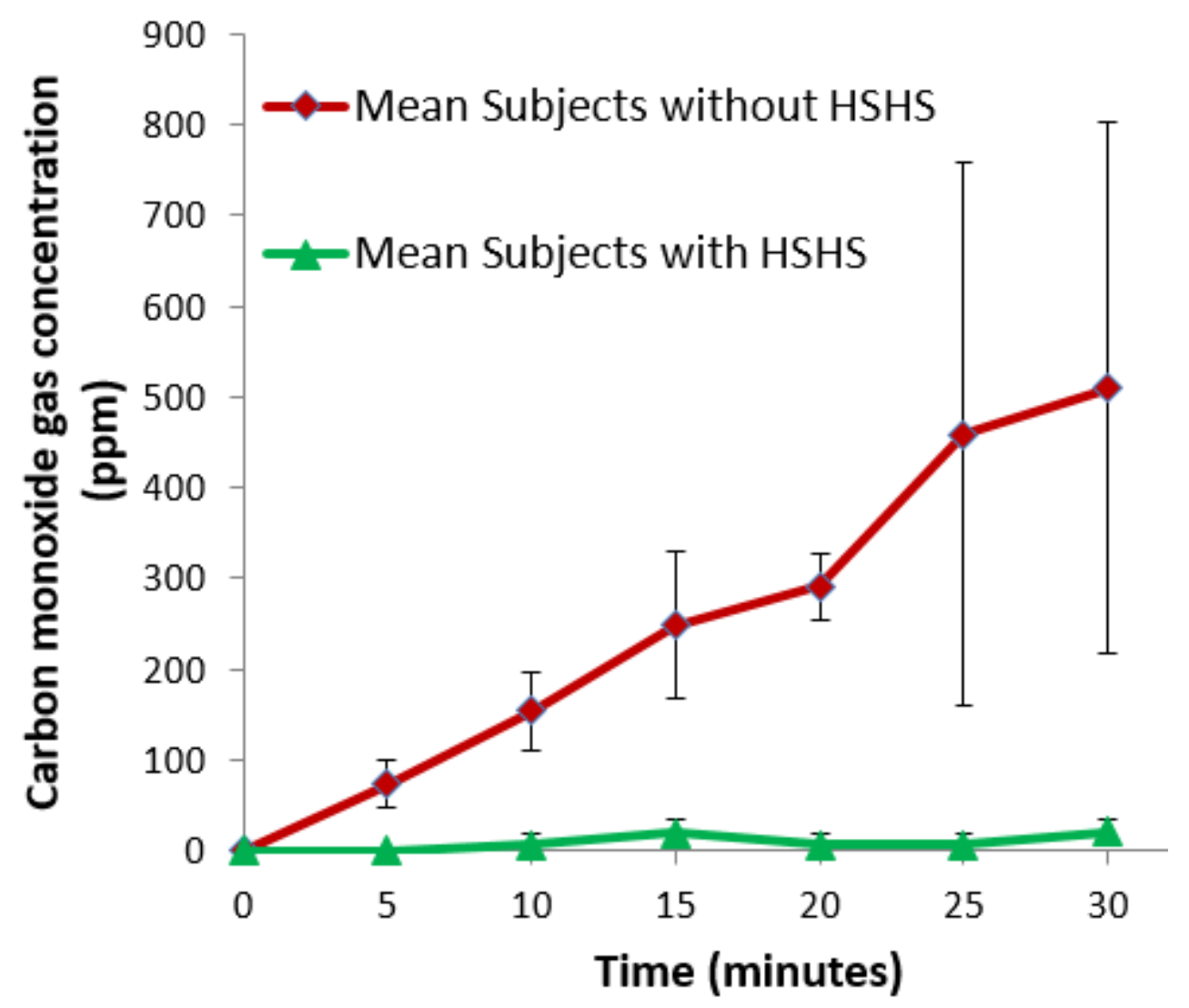

Figure 4. The average carbon monoxide gas concentration for the four subjects versus time, with and without the use of the HSHS device; with the corresponded standard deviations.

As mentioned in the previous section, because the low number of samples (only 4 subjects), inferential statistics tests were needed to prove if the differences of smoke detection, between the non-use or the use of HSHS were significant or not. SPSS paired samples t-test is a procedure for testing whether the means of two metric variables ("Mean Without for the 4 subjects" and "Mean With for the 4 subjects" in our study) are equal in some population. SPSS paired samples t-test results can be taken seriously only 
if the difference scores between the two variables is normally distributed in our population. For this reason, the Kolmogorov-Smirnov test was performed (Table 1), in order to test the validity of the normality assumption required by the paired samples ttest. Regarding our results of "Without HSHS" part in Table 1, the "p-values for Kolmogorov-Smirnov Test" for 5, 10, 15, 20, 25 and 30 minutes (mn) were respectively $0.8,0.9,0.7,0.9,0.5$ and 0.9 that seem to be normally distributed on the population (pvalues > 0.05). Only for $0 \mathrm{mn}$, the distribution has no variance (Standard deviation equal to zero) for this variable. Therefore, for $0 \mathrm{mn}$, sample Kolmogorov-Smirnov Test cannot be performed. In addition, regarding our results of "With HSHS" part in Table 1, the "p-values for Kolmogorov-Smirnov Test" for 10, 15, 20, 25 and $30 \mathrm{mn}$ were respectively $0.4,0.4,0.4,0.4$ and 0.6 that seem to be normally distributed on the population (p-values >0.05). Only for $0 \mathrm{mn}$ and $5 \mathrm{mn}$ the distribution has no variance (Standard deviation equal to zero) for this variable. Therefore, for $0 \mathrm{mn}$ and $5 \mathrm{mn}$, sample Kolmogorov-Smirnov Test cannot be performed. Consequently, at least both with and without $10,15,20,25$ and $30 \mathrm{mn}$ samples are reasonable and represent a normal population distribution. Therefore, we can perform the t-test for 10, 15, 20, 25 and $30 \mathrm{mn}$. In Table 1, the "p-values for paired samples t-test" were equal or less than 0.05 only for 10, 15, 20 and $25 \mathrm{mn}$. Therefore, despite the limited number of samples (only 4 subjects), the difference between the non-use or the use of HSHS for 10, 15, 20 and $25 \mathrm{mn}$ was statistically significant. Consequently, the use of HSHS device reduced approximately, in average $95.9 \% \pm 28.2 \%, 91.8 \% \pm 37.5 \%, 97.8 \% \pm 15.7 \%$ and $98.5 \%$ $\pm 66.2 \%$ of second hand inhalation hookah smoke during respectively 10, 15, 20 and 25 $\mathrm{mn}$ of smoking in a $5.3 \mathrm{~m}^{3}$ unventilated room. On the other hand, Wilcoxon SignedRanks test was performed in Table 1 for the $5 \mathrm{mn}$ because, as mentioned previously, the variables don't meet the normality assumption required by the paired samples t-test. "pvalue for Wilcoxon Signed-Ranks test" was equal to 0.06 for the $5 \mathrm{mn}$ (>0.05). Therefore, the difference between the non-use or the use of HSHS for $5 \mathrm{mn}$ was not statistically significant.

The detector has scored non-zero value several times (Table 1) during the use of the HSHS device. This non-zero value may be due for two reasons. The first reason was that the subjects were not trained to smoke using the "Hand" so a part of the smoke may be leaked out in the air. In the normal case (without the use of the HSHS device), smoker inhales the smoke from the hookah hose, then exhales in the ambiance air. But using the HSHS device, the smoker was obligated to exhale smoke in the "Hand". The smoke leakage may be reduced if people get used to use the hand of the HSHS device. The second reason may be due to the smoke coming out from lungs during a break after smoking. It is complicated to treat this second leakage as it is related to the individual smoking habits. Some smokers do not inhale smoke completely to their lungs as the subject \#4 case (Table 1), for example. Zero CO leakage was measured during the use of HSHS device in this case. Hens, it is interesting to develop an inhalation "Hand" system to treat the two kinds of smoke leakage. 
Table 1. Carbon monoxide gas concentration (ppm) in the unventilated room, with and without the use of the HSHS device (for the 4 subject); with the associated mean, standard deviation (SD), statistical tests and differences between the nonuse and the use of the HSHS device.

\begin{tabular}{|c|c|c|c|c|c|c|c|c|}
\hline & & $\begin{array}{c}\mathbf{0} \\
\mathbf{m n}\end{array}$ & $\begin{array}{c}5 \\
\mathbf{m n}\end{array}$ & $\begin{array}{l}10 \\
\mathbf{m n}\end{array}$ & $\begin{array}{r}15 \\
\mathrm{mn}\end{array}$ & $\begin{array}{l}\mathbf{2 0} \\
\mathbf{m n}\end{array}$ & $\begin{array}{l}25 \\
\mathbf{m n}\end{array}$ & $\begin{array}{c}30 \\
\text { mn }\end{array}$ \\
\hline \multirow{7}{*}{ 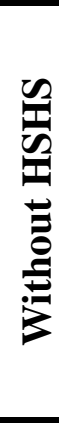 } & Subject \# 1 & 0 & 38 & 109 & 188 & 252 & 271 & 289 \\
\hline & Subject \# 2 & 0 & 76 & 161 & 229 & 291 & 346 & 380 \\
\hline & Subject \# 3 & 0 & 101 & 135 & 211 & 281 & 312 & 371 \\
\hline & Subject \# 4 & 0 & 78 & 210 & 367 & 339 & 907 & 996 \\
\hline & $\begin{array}{c}\text { p-values for Kolmogorov-Smirnov } \\
\text { Test }\end{array}$ & $\mathrm{a}$ & 0.8 & 0.9 & 0.7 & 0.9 & 0.5 & 0.5 \\
\hline & Mean Without for the 4 subjects & 0 & 73.3 & 153.8 & 248.8 & 290.8 & 459 & 509 \\
\hline & SD Without for the 4 subjects & 0 & 26.0 & 43.0 & 80.5 & 36.1 & 300.2 & 292.5 \\
\hline \multirow{7}{*}{ 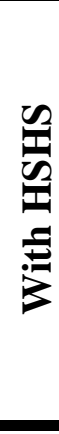 } & Subject \# 1 & 0 & 0 & 0 & 26 & 25 & 0 & 26 \\
\hline & Subject \# 2 & 0 & 0 & 25 & 28 & 0 & 27 & 29 \\
\hline & Subject \# 3 & 0 & 0 & 0 & 27 & 0 & 0 & 30 \\
\hline & Subject \# 4 & 0 & 0 & 0 & 0 & 0 & 0 & 0 \\
\hline & $\begin{array}{c}\text { p-values for Kolmogorov-Smirnov } \\
\text { Test }\end{array}$ & $\mathrm{a}$ & $\mathrm{a}$ & 0.4 & 0.4 & 0.4 & 0.4 & 0.6 \\
\hline & Mean With for the 4 subjects & 0 & 0 & 6.25 & 20.25 & 6.25 & 6.8 & 21.3 \\
\hline & SD With for the 4 subjects & 0 & 0 & 12.5 & 13.5 & 12.5 & 13.5 & 14.2 \\
\hline \multirow{6}{*}{ 童 } & $\begin{array}{l}\text { p-values for Wilcoxon Signed- } \\
\text { Ranks test }\end{array}$ & $\mathrm{a}$ & 0.06 & $\mathrm{~b}$ & $\mathrm{~b}$ & $\mathrm{~b}$ & $\mathrm{~b}$ & $\mathrm{~b}$ \\
\hline & p-values for paired samples t-test & $\mathrm{a}$ & $\mathrm{c}$ & 0.00 & 0.01 & 0.00 & 0.05 & 0.06 \\
\hline & (Mean Without)-(Mean With) & 0 & 73.3 & 147.5 & 228.5 & 284.5 & 452.2 & 487.7 \\
\hline & $\begin{array}{c}\text { SD of [(Mean Without)-(Mean } \\
\text { With)] }\end{array}$ & 0 & 26.0 & 43.5 & 93.5 & 45.9 & 303.9 & 341.1 \\
\hline & $\begin{array}{c}\text { (Mean Without)-(Mean With) in } \\
\%\end{array}$ & 0 & 100 & 95.9 & 91.8 & 97.8 & 98.5 & 95.8 \\
\hline & $\begin{array}{c}\text { SD of }[(\text { Mean Without }) \text {-(Mean } \\
\text { With) }] \text { in } \%\end{array}$ & 0 & 35.4 & 28.2 & 37.5 & 15.7 & 66.2 & 67.0 \\
\hline
\end{tabular}

a: The distribution has no variance for this variable. The Test cannot be performed.

$b$ : No need to perform the Wilcoxon Signed-Ranks test (because p-values for KolmogorovSmirnov Test were larger than 0.05), therefore the assumption required to perform the paired samples $t$-test was realized.

$c$ : The assumption required to perform the paired samples $t$-test was realized. 
This study was done for hookah smokers. However, a similar study can be done by using other kinds of smoking tools (Cigarette, Cigar, Pipe, etc.). As mentioned before, a single hookah session typically lasts for 45 minutes and may produce 50 to 100 times the smoke volume inhaled from a single cigarette (Lipkus et al., 2011; Rastam et al., 2011; Primack et al., 2012; Alzoubi et al., 2013; Maziak et al., 2013). Consequently, 30 minutes of hookah session may produce 33.3 to 66.7 times the smoke volume inhaled from a single cigarette. Therefore, in theory, to reach the results of 30 minutes of hookah smoking, the cigarette smoker has to smoke between 33 and 67 cigarettes. This is a high number of cigarettes, and the process needs a lot of time to be achieved. For this reason, this comparison allows to conclude that the HSHS device is more effective for hookah than for cigarettes smoking. This theory still needs validation in future works.

A simple use of the "Hand" alone (without the use of a HSHS device) was mentioned in a previous part. The "Hand" alone may become handy for low income smokers and help in partially preventing SHS contamination. Two hoses can be attached to the two "hand" gates localized on the right part of "Hand" image in Figure 2. The first hose end must be attached to the upper "hand" gate of image (or schema) in Figure 2. This hose is dedicated for the inhaled smoke. Its second end must be attached to the smoking tool inside the ETS. On the other hand, the second hose must be conducted far from the ETS (in the case of outdoor smoking), or outside the ETS in the case of indoor smoking. The use of the hand, by its own, without the HSHS device has two downsides. The first one is the smoke coming directly from burning the hookah's charcoals. The smoke is not evacuated and contaminates the ETS. The second one is that the smoker can't properly look at the exhaled smoke. Therefore, the smoker loses the HSHS device pleasure, of seeing his exhaled smoke. Consequently, the HSHS device attracts smokers more than the "Hand" alone. On the other hand, several HSHS device's options are being developed to attract smokers and reduce SHS, such as the light of several colors that the smoker can enjoy looking at, the automatic regulator smoke concentration, the drink bar on the extremities and the cupboard in the lower part (Figure 1).

When a person smokes normally without the use of the HSHS device, he has the choice to exhale the smoke inside the ETS, toward his desired direction. However, when a smoker uses the HSHS device, he doesn't have the choice because exhaled hose is fixed in one position inside the HSHS device. Therefore, an electronic remote control in the "hand" must be developed, to allow each smoker to choose his exhaled smoke direction inside the HSHS device. Hence, when the electronic remote control is available, a new option will be added which is: the smoke games inside the HSHS device. For example, an air soccer table inside the HSHS with a very light air ball guided by smoker's exhalations. On the other hand, to evacuate HSHS device, two methods may be used. The first method consists of extracting the air from the HSHS device by a vacuum pomp and throwing it outside or far from the ETS. This first way was used in this study and it was very efficient. A second method is based on the air filtering that necessitates the development of a dedicated smoke filter. 
Progress in tobacco control policy making has occurred worldwide. However, several countries confront problems in the application of tobacco control laws (Li et al., 2003; Hamer et al., 2010; Shiue et al., 2014; Nakkash et al., 2018). In particular, Lebanon ratified the Framework Convention on Tobacco Control (FCTC) in 2005, but until now, tobacco control policies remain rudimentary and not evidence-based (Nakkash et al., 2018). In such countries, where ETS laws are not respected, it may be a good solution when government decreases strictness of laws by authorizing smoking in crowded environments, only by using a reduced environmental smoking device like the HSHS. In addition, this device should be tested for its practicality and evaluated by potential customers and owners of smoking places (Marketing Feasibility), in the aim to have an idea on: the percentage of smokers who are willing to use it; and the number of smoking places who will be willing to consider making it available in their shops.

\section{CONCLUSIONS}

We have shown in this paper a concept of a new "Healthy Second Hand Smoke (HSHS)" device used to limit SHS contamination in an ETS and to offer a healthy environment around the smoker. It was achieved by isolating the smoke in a dedicated chamber from the surroundings. The $\mathrm{CO}$ concentration in a smoking environment was compared with and without the "HSHS" device. The use of HSHS device reduces approximately, in average $95.9 \% \pm 28.2 \%, 91.8 \% \pm 37.5 \%, 97.8 \% \pm 15.7 \%$ and $98.5 \% \pm 66.2 \%$ of second hand inhalation hookah smoke during respectively 10,15 , 20 and $25 \mathrm{mn}$ of smoking in a $5.3 \mathrm{~m}^{3}$ unventilated room. HSHS device was intended for smoking in an enclosed environment while protecting nonsmokers. This new concept can find many adepts for enclosed uses in homes, restaurants, nightclubs...

\section{ACKNOWLEDGMENT}

The authors would like to thank Bassam Hajj and Hala Jaber for editing the paper, Philippe Moussallem, Chady Moussallem, Siham Jocmek and Edward Nassif for their technical discussions, and the four volunteers that participated to collect the data for this study: Sanaa Moussallem, Rania Nassif, Wael Moussallem and Georges Jocmek.

\section{REFERENCES}

Alzoubi, K.H.; Khabour, O.F.; Azab, M.; Shqair, D.M.; Shihadeh, A.; Primack, B.; Eissenberg, T. 2013. CO exposure and puff topography are associated with Lebanese waterpipe dependence scale score.Nicotine Tob. Res. 15: 1782-1786.

Arlene MB, Elizabeth CM, Patrick B, et al. 2011. A Randomized Trial of Air Cleaners and a Health Coach to Improve Indoor Air Quality for Inner-City Children with Asthma and Secondhand Smoke Exposure. Arch Pediatr Adolesc Med. 165(8): 741-748. 
Anne Betzner, Raymond G. Boyle, Ann W. St. Claire. 2016. Price-Minimizing Behaviors in a Cohort of Smokers before and after a Cigarette Tax Increase. Int. J. Environ. Res. Public Health. 13: 608.

Chen, J.J.; Ho, S.Y.; Au, W.M.; Wang, M.P.; Lam, T.H. 2015. Family Smoking, Exposure to Secondhand Smoke at Home and Family Unhappiness in Children. Int. J. Environ. Res. Public Health. 12: 14557-14570.

Coggins CR, Gaworski CL. 2008. Could charcoal filtration of cigarette smoke reduce smoking-induced disease? a review of the literature. Regul Toxicol Pharmacol. 50(3): 359-365.

Farsalinos, Konstantinos; Voudris, Vassilis; Poulas, Konstantinos. 2015. Are Metals Emitted from Electronic Cigarettes a Reason for Health Concern? A RiskAssessment Analysis of Currently Available Literature.Int. J. Environ. Res. Public Health. 12(5): 5215-5232.

Gao, Y.; Shi, L. 2015. Mindfulness, Physical Activity and Avoidance of Secondhand Smoke: A Study of College Students in Shanghai. Int. J. Environ. Res. Public Health. 12: 10106-10116.

GBD 2013 Risk Factors Collaborators; Forouzanfar, M.H.; Alexander, L.; Anderson, H.R.; Bachman, V.F.;Biryukov, S.; Brauer, M.; Burnett, R.; Casey, D.; Coates, M.M.; et al. 2015. Global, regional, and national comparativerisk assessment of 79 behavioural, environmental and occupational, and metabolic risks or clusters of risksin 188 countries, 1990-2013: A systematic analysis for the Global Burden of Disease Study 2013. Lancet. 386: 2287-2323.

Gerald A. Long. 2014. Comparison of Select Analytes in Exhaled Aerosol from ECigarettes with Exhaled Smoke from a Conventional Cigarette and Exhaled Breaths.Int. J. Environ. Res. Public Health. 11.

Hajek, P; Etter, JF; Benowitz, N; Eissenberg, T; McRobbie, H. 2014. Electronic cigarettes: review of use, content, safety, effects on smokers and potential for harm and benefit. Addiction (Abingdon, England) 109(11): 1801-10.

Hamer, M.; Stamatakis, E.; Batty, G.D. 2010. Objectively assessed secondhand smoke exposure andmental health in adults: Cross-sectional and prospective evidence from the Scottish Health Survey.Arch. Gen. Psychiatr. 67: 850-855.

International Agency for Research on Cancer IARC. 2002. Monographs Programmme on the Evaluation of Carcinogenic Risks to Human, 83. http://www.iarc.fr

JiemingZhong, Shuangshuang Cao, Weiwei Gong, FangrongFei, Meng Wang. 2016. Electronic Cigarettes Use and Intention to Cigarette Smoking among NeverSmoking Adolescents and Young Adults: A Meta-Analysis. Int. J. Environ. Res. Public Health. 13: 465.

Kamal Chaouachi. 2009. Hookah (Shisha, Narghile) Smoking and Environmental Tobacco Smoke (ETS). A Critical Review of the Relevant Literature and the Public Health Consequences. Int. J. Environ. Res. Public Health. 6: 798-843.

Kiter, G.; Ucan, E.; Ceylan, E.; Kilinc, O. 2000. Water-pipe smoking and pulmonary functions.Resp. Med. 94: 891-894. 
Linda Haddad, Omar El-Shahawy, RoulaGhadban, Tracey E. Barnett, Emily Johnson. 2015. Waterpipe Smoking and Regulation in the United States: A Comprehensive Review of the Literature. Int. J. Environ. Res. Public Health 12.

Linmiao Zeng, Xiaolian Yu, Tingting Yu, Jianhong Xiao, Yushan Huang. 2016. "Interventionsfor smoking cessation in people diagnosed with lung cancer". Cochrane Lung Cancer Group.

Lipkus, I.M.; Eissenberg, T.; Schwartz-Bloom, R.D.; Prokhorov, A.V.; Levy, J. 2011. Affecting perceptions of harm and addiction among college waterpipe tobacco smokers. Nicotine Tob. Res. 13: 599-610.

Li, C.; Unger, J.B.; Schuster, D.; Rohrbach, L.A.; Howard-Pitney, B.; Norman G. 2003. Youths'exposure to environmental tobacco smoke (ETS): Associations with health beliefs and socialpressure. Addict. Behav 28: 39-53.

Ng, M.; Freeman, M.K.; Fleming, T.D.; Robinson, M.; Dwyer-Lindgren, L.; Thomson, B.; Wollum, A.; Sanman, E.; Wulf, S.; Lopez, A.D.; et al. 2014. Smoking prevalence and cigarette consumption in 187 countries, 1980-2012. JAMA. 311: $183-192$.

Maziak, W. 2013. Waterpipe smoking. In Principles of Addiction; Miller, P.M. Chapter 90. Ed.;Academic Press: San Diego, CA, USA. pp. 891-900.

Moussallem M, Valette P J, Traverse-Glehen A, Houzard C, Jegou C, and Giammarile F. 2012. New strategy for automatic tumor segmentation byadaptive thresholding on PET/CT images. J. Appl. Clin. Med. Phys. 13: 236-251.

Nakkash RT, Torossian L, El Hajj T et al. 2018. The passage of tobacco control law 174 in Lebanon: Reflections on the problem, policies and politics. Health Policy and Planning. 33(5): 633-644.

PDQ Adult Treatment Editorial Board. 2016. "Small Cell Lung Cancer Treatment (PDQ®)". PDQ Cancer Information Summaries.

Primack, B.A. Longacre, M.R. Beach, M.L. Adachi-Mejia, A.M. Titus, L.J. and Dalton, M.A. 2012. Association of established smoking among adolescents with timing of exposure to smoking depictedin movies. J. Natl. Cancer Inst. 104: 549-555.

Rastam, S.; Eissenberg, T.; Ibrahim, I.; Ward, K.D.; Khalil, R.; Maziak, W. 2011. Comparative analysisof waterpipe and cigarette suppression of abstinence and craving symptoms. Addict. Behav. 36: 555-559.

Regan, A.K.; Promoff, G.; Dube, S.R.; Arrazola, R. 2013. Electronic nicotine delivery systems: Adult use and awareness of the "e-cigarette" in the USA. Tob. Control. 22: 19-23.

Rowell, Temperance R; Tarran, Robert. 2015. "Will Chronic E-Cigarette Use Cause Lung Disease?".American Journal of Physiology. Lung Cellular and Molecular Physiology: ajplung.00272.2015.

Shiue, I. 2014. Modeling the Effects of Indoor Passive Smoking at Home, Work, or Other Households on Adult Cardiovascular and Mental Health: The Scottish Health Survey, 2008-2011. Int. J. Environ. Res. Public Health. 11: 3096-3107.

Tayyarah, R.; Long, G.A. Comparison of select analytes in aerosol from e-cigarettes with smoke from a conventional cigarette and with ambient air.Regul.Toxicol.Pharmacol. 2014, in press, doi: 10.1016/j.yrtph.2014.10.010. 
Vassiliki Mantziou, Constantine I. Vardavas, Eleni Kletsiou, Kostas N. Priftis. 2009. Predictors of Childhood Exposure to Parental Secondhand Smoke in the House and Family Car. Int. J. Environ. Res. Public Health. 6.

Wampler DA, Miller-Leiden S, Nazaroff WW, et al. 1995. Effectiveness of smokeless ashtrays. J Air Waste Manag Assoc. 45(6): 494-500.

WHO Report on tobacco smoke and child health: consultation report. WHO: Geneva,Switzerland, 1999.

WHO Study Group on Tobacco Product Regulation. Advisory Note: Waterpipe Tobacco Smoking:Health Effects, Research Needs and Recommended Actions by Regulators; World Health Organization: Geneva, Switzerland, 2005. 